\title{
A pessoa com o diagnóstico de uma condição genética como informante-chave do campo das doenças raras - uma perspectiva pela sociologia do diagnóstico
}

\author{
The individual with the diagnosis of a genetic condition as a key \\ informant in the field of rare diseases - a perspective from the \\ sociology of diagnosis
}

Rogério Lima Barbosa (https://orcid.org/0000-0003-1021-8794) ${ }^{1}$

\footnotetext{
${ }^{1}$ Centro de Estudos Sociais, Universidade de Coimbra. Coimbra Portugal. Faculdade de economia. Av. Dias da Silva 165. 3004-512. Coimbra Portugal. rogerio.limab@gmail.com

\begin{abstract}
Adopting a different viewpoint from most of the work in the field of so-called rare diseases, this paper crosses the boundaries of the associations to reach people living with the diagnosis of a genetic condition, which is understood as being a rare disease, namely neurofibromatosis (NF). In this respect, the incipient Sociology of Diagnosis is utilized to identify both the impact and the consequences of the diagnosis in people's lives. As a result, the consensus is that it is necessary to transcend the charitable outlook on people who experience the diagnosis of a genetic condition, by perceiving the patient as a key informant in order to collect input to improve health services and our social relations.
\end{abstract}

Key words Rare disease, Genetic condition, Sociology of diagnosis, Health.
Resumo Em um panorama diferente da maioria dos trabalhos do campo das chamadas doenças raras, esse artigo transpõe os limites das associações para chegar até as pessoas que vivem com o diagnóstico de uma condição genética e entendida como doença rara, a Neurofibromatose (NF). Nesse trajeto, utiliza-se da ainda nascente Sociologia do Diagnóstico para identificar tanto o impacto quanto as consequências do diagnóstico na vida das pessoas. Como resultado entende-se que devemos superar o olhar caritativo sobre as pessoas que vivenciam o diagnóstico de uma condição genética, o doente, para, como um informante-chave, captar as contribuições para melhorar os serviços de saúde e as nossas relações sociais.

Palavras-chave Doença rara, Condição genética, Sociologia do diagnóstico, Saúde 


\section{Introdução}

A partir do final dos anos de 1980 há um maior reconhecimento das doenças raras como um assunto de relevância médica e social ${ }^{1}$. Seguramente, as ações de sensibilização realizadas pelas Organizações de Pacientes (OPs) fazem parte de um dos motivos para o aumento de tal interesse. Formadas por familiares e pessoas com a atenção posta nas chamadas "doenças raras" as OPs atuam em um modelo guarda-chuva, para representarem todas as doenças raras (segundo a associação europeia Eurordis, existem mais de seis mil tipos de doenças raras, são entendidas como aquelas que incidem em 1 de cada 2000 nascidos, afetam a qualidade de vida das pessoas, são potencialmente fatais e $80 \%$ possuem causa genética), e num modo de ativismo pelo advocacy. As atividades realizadas sob essa bandeira estão relacionadas a regulamentação de políticas que incentivem a pesquisa e a comercialização de medicamentos para as doenças raras. Esses medicamentos são chamados de drogas órfãs e foi o termo criado pela indústria farmacêutica e de biotecnologia para caracterizarem as drogas voltadas às doenças raras $^{2}$. Debruçar-se sobre a dinâmica do campo das doenças raras a partir da visão das OPs, ajudanos a perceber os esforços na aprovação de suas demandas.

Nos EUA, em 1983, as OPs conseguiram realizar a aprovação do Orphan Drug Act, constituindo-se o primeiro regulamento para as drogas órfãs. Esse regulamento se figura como modelo para outras partes do mundo. E, na Europa, nomeadamente em França, além de ter sido a inspiração para a promulgação do documento europeu, as atividades promovidas pelas OPs francesas, até a sua aprovação, foram as mesmas ${ }^{3}$ : fundação de uma associação do tipo guarda-chuva, - National Organization for Rare Disease, nos EUA, e a Eurordis, em França -, promoção de uma maratona televisiva para angariação de fundos $(M D A$ Jerry Lewis Labor Day nos EUA e AFM Telethon em França) e o exercício do advocacy para a aprovação do regulamento (1983 e 1999). De modo geral, a criação de uma OP no modelo guardachuva e com foco no advocacy é comum em qualquer espaço onde as demandas para doenças raras estão em pauta, inclusive em terras brasileiras.

No Brasil, apesar de termos organizações que atuam no modelo de OPs, elas não alcançam a mesma estrutura e transparência financeira de suas congêneres internacionais. Poucas são as que divulgam os relatórios financeiros, as fontes de financiamento e as parcerias para angariação de fundos. Também, não existe qualquer maratona televisiva ou ações de sensibilização que possam ter o mesmo alcance de massa. E, apesar disso, em fevereiro de 2019, a primeira-dama Michele Bolsonaro realizou um pronunciamento sobre as doenças raras na tribuna da Câmara dos Deputados para criação da Coordenação dos Raros. Interessante apontar que a proposta desta coordenação acontece sob a Política Nacional de Atenção Integral às Pessoas com Doenças Raras, divulgada pela Portaria no 199/2014 do Ministério da Saúde (MS).

A Portaria no 199/2014 contou com a participação das associações civis em sua elaboração, possui incentivos financeiros de custeio para as equipes de serviços de atenção especializada em doenças raras e aponta a necessidade em combater os estigmas e preconceitos impregnados na vida daqueles que vivem com alguma doença $\mathrm{rara}^{4}$. Ao iluminar o combate ao preconceito e ao estigma, a Portaria no 199/2014 se afasta do Lobby para as drogas órfãs e vira-se para a importância de reconhecer a realidade de $97 \%$ da população que convive com alguma doença rara e que não possui tratamento medicamentoso (conforme documento da Interfarma, 3\% das doenças raras possuem medicamento disponível ${ }^{5}$ ). Ademais, alinha-se a estudos que enxergam os constrangimentos da influência da indústria farmacêutica no campo, como a constatação que mesmo diante do aumento dos produtos voltados para as doenças raras após as aprovações dos regulamentos para drogas órfãs não estão claras as vantagens advindas das declaradas inovações tecnológicas ${ }^{6}$.

Se por um lado, os trabalhos com as OPs levantam o entusiasmo em perceber a atuação do mercado no campo, por outro, as pesquisas realizadas diretamente com associações europeias (Eurordis e Association Française contre les Myopathies - AFM, por exemplo) descobrem o constrangimento da relação do mercado com as organizações de pacientes. Além disso, declaram que para entender a influência das indústrias e seus resultados é necessário realizar investigações com pessoas "de dentro" não somente das associações (principalmente os associados) como com indivíduos que experienciem o viver com o diagnóstico de alguma entendida doença rara ${ }^{7}$.

Em consonância com esses trabalhos, esse artigo apresenta um diálogo a partir "de dentro" do campo. E se fundamenta em parte dos resultados da pesquisa doutoral desenvolvida na Universidade de Coimbra, finalizada em 2018.

A Tese doutoral foi uma pesquisa autoetnográfica, qualitativa, exploratória e comparativa 
entre o Brasil, a Inglaterra e Portugal, focada em uma doença rara específica, a Neurofibromatose do tipo 1 (NF). Tendo em vista a minha própria experiência como ativista, pai de uma criança com o diagnóstico da NF, parte do objeto de estudo e entrevistado em outras pesquisas, o método autoetnográfico foi fundamental para reconhecer e situar a minha presença no campo e perseguir o equilíbrio científico entre o auto experiência pessoal, o etno - a experiência cultural e a grafia - a análise sistemática dos dados da pesquisa ${ }^{8}$. A comparação do ambiente brasileiro com Portugal justifica-se pela existência de publicações referentes a OPs originados a partir de projetos entre a Universidade de Coimbra, em Portugal, em parceira com Mines Paris Tech, em França. Em relação a Inglaterra, a Universidade de Exeter possui estudos ligados a NF, dentro do departamento de Sociologia e Antropologia, e realizam trabalhos pioneiros sobre a Sociologia do Diagnóstico. A pesquisa doutoral foi aprovada pelo Comitê de Ética da Universidade de Exeter (Social Sciences and International Studies College Ethics Committee) em 13/01/2016. Foram elaborados quatro documentos relacionados com as entrevistas: Anexo 1 - Sinopse do Projeto, Anexo 2 - Apresentação, Anexo 3 - Formulário de Informações e Anexo 4 - Formulário de Participação. Esses documentos eram enviados, via email, no momento da confirmação de cada entrevista. No encontro presencial e antes do início da gravação do áudio, a pessoa a ser entrevistada recebia todos os documentos impressos em mãos. A gravação somente se iniciava após a solução das eventuais dúvidas referentes a investigação e a leitura dos documentos, principalmente, do formulário de participação. Esse era impresso em duas vias. Ambas eram assinadas pelo participante e pelo pesquisador. E cada um guardava uma via do formulário devidamente assinada. Realizaram-se 27 entrevistas em profundidade (Brasil: três mulheres com o diagnóstico e quatro familiares, um homem com o diagnóstico e dois familiares; Inglaterra: duas mulheres com o diagnóstico e quatro familiares; Portugal: quatro mulheres com o diagnóstico e duas familiares, três homens com o diagnóstico e um familiar). Os familiares foram pais, mães, tio/as e irmão/ãs. A pessoa mais nova tinha 19 anos e a mais velha 77 anos. Para a pesquisa doutoral, os nomes pessoais foram substituídos pelos de figuras históricas e de importância política/social para o Brasil. Neste presente artigo, mantenho o mesmo formato de caracterização da pessoa entrevistada para a Tese, nome/idade/ocupação/país. Quando reali- zada com familiar acrescento o parentesco. Com a ideia de utilizar foto(s) ou imagem(ns) como estímulos para o desenvolvimento da entrevista, utilizei a foto-elicitação como técnica de recolha de informações. Adicional a essa, a História de Vida Focal, foi essencial para centralizar a entrevista no diagnóstico da NF e captar a experiência da pessoa no processo de adoecimento.

Para o presente trabalho, resgato parte da pesquisa doutoral que aborda a NF para avançar com a apresentação dos trabalhos entendidos como basilares para a Sociologia do Diagnóstico e, nesta perspectiva, apresento parte dos resultados alcançados quando assumimos a centralidade das pessoas que possuem o diagnóstico de uma doença rara, no caso a NF, como informantes-chave.

\section{A Neurofibromatose}

A Figura 1, que abre esse capítulo é do cartunista, pesquisador, pai de uma pessoa com NF e médico, Lor. Foi utilizada na Tese doutoral e em encontros científicos onde abordava o impacto do diagnóstico. É uma imagem forte e conclusiva de como nos sentimos ao ouvir o diagnóstico de uma condição genética rara. Porque, enquanto a (pouca) informação que vem seguida do diagnóstico nos coloca em uma verdadeira "busca na selva”, permeada de desespero, dor e sofrimento, também, demonstra a ignorância de não sabermos o impacto daquela informação na vida de quem a tem (afinal, não vemos qualquer reação do bebê ao colo da mãe).

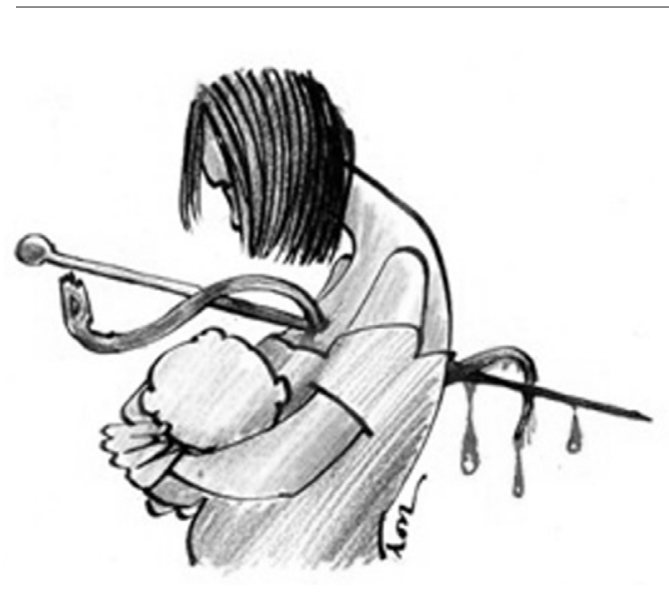

Figura 1. O impacto do diagnóstico de uma condição nomeada como "Doença Rara" 
No contexto biomédico, a NF está bem definida como uma variação de um grupo de manifestações genéticas que afetam o tecido nervoso, as Neurofibromatosis ${ }^{9}$. Por ter sido descrita pelo patologista alemão Friedrich Von Recklinghausen, em 1882, é frequente ser nomeada como a doença de Von Recklinghausen e, atualmente, sabe-se que o gene da NF1 está localizado no braço longo do cromossomo $17 \mathrm{q} 11.2^{9}$. A NF é uma desordem autossómica dominante com penetrância comple$\mathrm{ta}^{10}$. A possibilidade da transmissão por hereditariedade é de $50 \%$ e, quando o gene existe, a sua capacidade de manifestação é de $100 \%{ }^{11}$. É uma alteração genética cuja ocorrência é independente da raça ou grupo étnico e além da probabilidade de herdar a mutação genética por hereditariedade, a NF "é considerada a mutação autossómica dominante espontânea "nova" mais comum nos seres humanos"12. As complicações da NF são variáveis, imprevisíveis e comuns, que vão desde dificuldades de aprendizado, pressão arterial alta e sintomas gastrointestinais até o desfiguramento e tumores malignos ${ }^{13}$. A severidade da NF é muito variável e a sua ocorrência não pode ser prevista, mesmo entre pessoas da mesma família ${ }^{14}$.

Como $80 \%$ das chamadas doenças raras, a etiologia da NF é genética. Além do mais, a população que convive com a NF está entre as mais de $90 \%$ do conjunto das doenças raras que não possuem medicamento disponível. A variedade fenotípica, a falta de medicamentos, a dificuldade de aconselhamento e a etiologia genética são partes inerentes a realidade do campo das doenças raras.

A precisão da NF no gene, não é a mesma quanto ao seu entendimento como doença. Em uma pesquisa realizada pelos termos Neurofibromatosis e Type 1, em julho de 2017, no buscador de trabalhos científicos PubMed, verificou-se que a NF pode ser caracterizada como doença, condição, desordem ou síndrome. E, especificamente ao seu reconhecimento como doença, a pesquisa doutoral demonstrou a dificuldade de a caracterizá-la como tal:

Olha, essa pergunta é difícil para eu expressar [O que é a NF para você??]. Por que é tanta coisa que é difícil de eu te dizer uma palavra ou um desenho do que é neurofibromatose. Eu acho uma coisa complicada de falar, de te dizer, como que eu poderia... Você me ajuda a dizer o que é. Doença ela é? Ou ela não é considerada doenças? Chica (74 anos, professora aposentada, Brasil).

A componente social da condição é um item intrínseco na sua percepção, uma vez que a ideia sobre o que é a NF se relaciona com as manifes- tações do gene e a influência que os outros possuem sobre as pessoas com o diagnóstico. O peso da componente social é relatado nos trabalhos de cariz médico e tendem a evidenciar a fragilidade que as pessoas com o diagnóstico enfrentam no campo social.

A resistência entre o conceito biomédico da NF e sua aceitação social, encoraja o debate sobre o próprio entendimento do que é doença. E, também, cabe relembrar que a observação das dinâmicas pessoais ao redor da condição foi parte da proposta de Rabinow para biossociabilidade ${ }^{15}$.

Existem ainda, por exemplo, os grupos de neurofibromatose onde os membros se encontram para partilhar suas experiências, fazer lobby para as suas demandas, educação para as crianças, reorganizar o ambiente familiar e assim por diante. Isso é o que eu chamo de biossociabilidade ${ }^{15}$.

Os diferentes assuntos que entrecruzam a NF (variabilidade fenotípica, trato com a indústria farmacêutica, participação das associações, estigma, preconceito, biossociabilidade e foco na informação genética) estão presentes em qualquer tema que aborde as doenças raras, na área das ciências sociais e humanas. E mesmo que as propostas para biossociabilidade ainda precisem de maiores investigações ${ }^{16}$, elas são amplamente aceitas nos trabalhos do campo das condições genéticas e dentro do contexto da era genômica ${ }^{17}$. Com essa consciência, é possível afirmar que as observações colhidas em torno da NF possuem o potencial de serem compartilhadas com qualquer outra realidade onde o imperativo do gene marca a dinâmica social.

Como veremos adiante, o olhar para o campo da NF a partir da Sociologia do Diagnóstico tem o grande contributo de possuir a base comum na relação entre o conceito biomédico e a aceitação social da "doença".

\section{Panorama da sociologia do diagnóstico}

Desde a década de setenta, pesquisadores e profissionais das áreas da saúde e da sociologia identificam o diagnóstico como uma ferramenta de classificação ilustrativa do poder médico e um evento que impacta na dinâmica individual, familiar, social e no planejamento do sistema de saúde. Apesar de diferentes trabalhos em torno do diagnóstico, foi na segunda metade dos anos 90 que, pela primeira vez, há a menção sobre a Sociologia do Diagnóstico (SD). O tema ainda está ganhando o seu corpo teórico e existem pesquisadores/as dedicados/as ao assunto, principalmente, em Nova Zelândia e Inglaterra. 
No Brasil, por meio de uma parceria entre a Universidade de Exeter, da Inglaterra, e a Universidade Federal Fluminense, entre os dias 24 e 27 de abril de 2017, com a intervenção de diferentes pesquisadores/as, participantes de associações e público em geral, foi realizado o primeiro workshop sobre a SD em terras nacionais, sob o título: Sociologia do Diagnóstico - Conceitos e Aplicações. Afora a partilha do entusiasmo entre os presentes, os trabalhos erigidos após esse marco brasileiro, refletem o fortalecimento do interesse sobre o assunto e a contribuição para os estudos relacionados ao processo saúde-doença.

Em 1978, Blaxter ${ }^{18}$ indicou que o diagnóstico possui a característica de ser uma categorização e um processo. A categorização refere-se a nomeação dos sintomas da doença que são vivenciados pela pessoa, tem as funções de dar um retorno à demanda de saúde e indicar as ações para o seu restabelecimento. Blaxter também reflete sobre a indispensável necessidade da categorização como fundamento para a organização dos sistemas de saúde, tanto local quanto internacionalmente. Essa categorização visa não somente a organização dos serviços como, também, gerar a possibilidade de comparabilidade entre os mesmos. Para ela, as classificações definidas pela Organização Mundial da Saúde, mais precisamente a Classificação Estatística Internacional de Doenças e Problemas Relacionados com a Saúde - CID, cumprem a função de organização e comparabilidade dos serviços de saúde tanto local quanto entre países.

Apesar da pretensa objetividade da categorização do diagnóstico, sabe-se que tanto ele quanto o seu par, a prescrição do possível tratamento, depende de diversos fatores a disposição do profissional da medicina e está coberto por incertezas $^{19}$. No entanto, essa constatação não diminui a importância do diagnóstico para a saúde e para a organização social.

Ainda conforme Blaxter a categorização é o objetivo final do processo de diagnóstico. Esse processo pode ser tanto dedutivo quanto indutivo e refere-se a utilização de recursos, tecnológicos ou não, segue um encadeamento lógico, científico e, independente da complexidade, a sua função é chegar até a categorização dos sintomas.

O texto de Blaxter é uma boa demonstração da constelação que se envolve em torno do diagnóstico. Antes de mais, o diagnóstico é uma interação pessoal. Somente existe pela relação, no mínimo, entre dois indivíduos: o profissional e aquele que possui alguma demanda de saúde. E mesmo que o excesso de tecnologia se torne cada vez mais presente e controlador das ações dos envolvidos, o diagnóstico sempre dependerá da prática médica e da experiência vivida pela pessoa $^{20}$. É constituído por momento(s) onde a qualidade da interação entre as pessoas impactam diretamente no resultado do diagnóstico e nas prescrições das ações a serem tomadas para a terapêutica. Ainda que esteja envolto mais por dúvidas do que certezas, o diagnóstico é que apontará o prognóstico dos sintomas, para todos os envolvidos.

O sociólogo Phil Brown ${ }^{21}$ foi um dos poucos estudiosos que chamaram a atenção para a necessidade de uma Sociologia do Diagnóstico. No trabalho que o autor nomeia a Sociologia do Diagnóstico, Brown enfatiza a construção social ao redor da doença. Sem precisar dedicar o seu tempo na diferenciação entre a visão normativa, naturalista ou híbrida sobre o conceito de doença, entende-se que Brown alinha-se a visão que doença é "um termo natural com conotações normativas". Por essa via, o autor concentra a sua argumentação no processo social de identificação/descoberta da doença e na experiência do sofrimento, sintetizados no Quadro 1.

De acordo com o autor, o quadro tem o objetivo de apresentar os eixos de interesse da SD e reconhecer que o entendimento social de doença pode estar em mais de um quadrante.

$\mathrm{O}$ autor ainda destaca a importância do envolvimento de cientistas sociais na área da saúde,

Quadro 1. Tipologia das condições e definições.

\begin{tabular}{|l|l|l|}
\hline & \multicolumn{1}{|c|}{ Condição geralmente aceita } & \multicolumn{1}{|c|}{$\begin{array}{c}\text { Condição questionável ou aceita de } \\
\text { forma restrita }\end{array}$} \\
\hline $\begin{array}{l}\text { Definição biométrica } \\
\text { aceita }\end{array}$ & $\begin{array}{l}\text { 1. Condições definidas rotineiramente } \\
\text { (doenças infecciosas, doenças crônicas, } \\
\text { lesões) }\end{array}$ & $\begin{array}{l}\text { 2. Definições medicalizadas (transtorno } \\
\text { disfórico pré-menstrual, fadiga crônica, } \\
\text { síndrome da dor crônica) }\end{array}$ \\
\hline $\begin{array}{l}\text { Definição biométrica } \\
\text { não aceita, ou existência } \\
\text { de conflitos na definição }\end{array}$ & $\begin{array}{l}\text { 3. Definições contestadas (doenças } \\
\text { ocupacionais, doenças induzidas pelo } \\
\text { ambiente, sensibilidade química múltipla) }\end{array}$ & $\begin{array}{l}\text { 4. Definições potencialmente } \\
\text { medicalizadas (doenças a partir de } \\
\text { predisposições genéticas) }\end{array}$ \\
\hline
\end{tabular}


uma vez que são esses que estão na vanguarda da comunicação que a saúde e a doença são mais afetadas por questões políticas, econômicas e culturais do que necessariamente fatores biomédicos. Em relação ao diagnóstico, o autor realça que ele é a "voz da medicina" e contrasta com a "voz do mundo-real"; define os parâmetros do que é normal e anormal; demarca as barreiras profissionais e institucionais para o controle social e os sistemas de saúde, e autoriza a medicina a rotular e a lidar com as pessoas em nome de toda a sociedade.

Após o chamamento de Brown para a SD, à característica de categoria e processo do diagnóstico soma-se às consequências do diagnóstico. No prefácio de um dos livros seminais sobre a Sociologia do Diagnóstico, Put a name on it - Diagnosis in contemporany society, de Annemarie Jutel, Peter Conrad destaca que, apesar do diagnóstico ser um evento médico emblemático, o livro de Jutel consegue chamar a atenção para o seu entendimento como um evento com fortes raízes sociais e com consequências significativas ${ }^{22}$.

Jutel é uma das autoras mais citadas no campo da Sociologia do Diagnóstico e se esforça para produzir um esquema teórico que possa enquadrar a matéria como uma disciplina. Em From the bookshelf of a sociologist of diagnosis: A review essay ${ }^{23}$, Jutel faz um apanhado das áreas e dos trabalhos teóricos que sustentam a suposta disciplina. Esse artigo é uma feliz metáfora a estante de um estudioso da SD. Nessa proposta, Jutel, claramente, se empenha em apresentar os trabalhos que fornecem à SD um corpo teórico de disciplina e, assim, chama a atenção não somente à relação médico/paciente no momento do diagnóstico, mas também às tensões existentes e aos resultados despoletados na própria sociedade.

Como a intenção é apenas a de apresentar as linhas estruturais da SD, porque os fundamentos teóricos estão dispostos no artigo de Jutel, falta destacar, por agora, o carácter dinâmico do diagnóstico. Pois antes de ser um ato de mera comunicação médica a um agente passivo, é um evento de interação humana, organizado em momento(s), com características de categorização e processo que gera consequências tanto à pessoa que recebe o diagnóstico quanto para os demais envolvidos.

\section{Os resultados a partir da sociologia do diagnóstico}

Ao considerarmos o quadro proposto por Brown, vemos que a NF e as condições genéticas estarão assentes no quadrante 3 - Definições contestadas , e no 4 - Definições potencialmente medicalizadas. Ambas estão no eixo onde a definição biomédica não é aceita ou existe conflitos na sua aceitação. O reconhecimento do conflito serve para reafirmar a proposta de captar a percepção por parte da pessoa que convive com o diagnóstico frente as limitações causadas pelo gene e a estrutura social. Para tanto, partimos do entendimento que essas pessoas são informantes-chave que possuem a vantagem de ter "uma visão mais prática, mais personalizada, referindo-se a realidades que conhecem e fornecendo exemplos do quotidiano"24. Amplamente utilizado em investigações qualitativas, nas ciências sociais e humanas, o informante-chave é tanto a pessoa que pode inserir o/a investigador/a no campo de estudo como, também, a fonte de informações sobre a realidade investigada ${ }^{25}$. De partida, ao assumirmos a pessoa com o diagnóstico como informantes-chave percebemos a diferenciação das preocupações dos familiares e o distanciamento da proposta da biossociabilidade.

A partir do dinamismo empreendido pela Sociologia do Diagnóstico o informante-chave assume um papel ativo e, ao invés de observá-lo como carente de ajuda para a busca da cura, inverte-se a equação para percebermos a sua contribuição para a melhoria dos serviços de saúde, da própria comunidade e dentro da lógica do cuidado.

Ao contrário da busca pela cura que desencadeia um processo de produção do lucro e constitui obstáculos ao cuidado e à plena integração social das pessoas, assumimos a lógica do cuidado como uma atividade alinhada à tecnologia e a vida moderna onde a pessoa assume um papel ativo na produção de seu bem-estar, pois “a lógica do cuidado não está preocupada com a nossa doença e com o que podemos optar, mas concentra-se sobre o que nós fazemos" ${ }^{26}$. Assim, podemos elencar o que segue.

\section{Para evento e processo}

As entrevistas demonstraram que o diagnóstico era realizado em momento(s) planejado(s). No entanto, isso não significa que a nomeação da NF surgiu, obrigatoriamente, por causa de alguma demanda de saúde. Assim como houve diagnósticos realizados após longas investigações, algumas pessoas receberam o diagnóstico quando crianças e em consultas de rotinas com o pediatra. Nestes casos, essas pessoas eram utilizadas como referência para o diagnóstico de familiares. 
Descobri quando a minha filha nasceu, não é?! [Aos 35 anos] Ela ainda estava deitada no berço, tinha acabado de nascer e tinha uma manchinha e eu disse a minha mulher, Pronto! é a minha fitha, tem uma mancha igual, então pronto. Passado duas horas, o pediatra entrou dentro do quarto para dizer que tinha corrido tudo bem, mas tinhathe chamado a atenção que a menina tinha a Neurofibromatose, foi aí então que eu descobri que eu era o portador. Francisco (52 anos, representante comercial, Portugal)

Se a característica específica da condição agiliza o processo do diagnóstico e o faz até para aqueles que não possuem qualquer queixa em relação a saúde, a investigação que inicia por um membro da família e por causa de alguma demanda de saúde, confirma a literatura que indica os longos percursos até a identificação das condições genéticas.

\section{A categorização}

As passagens acima elucidam o processo do diagnóstico em torno das condições genéticas. Em relação a NF, que possui o CID 10-85.0, percebeu-se que o conhecido "parâmetros de horror" ${ }^{27}$, observados pela pesquisadora da antropologia médica, Joan Ablon, refletem a representação social da NF na personagem do Homem -Elefante. A personagem foi vivida pelo inglês Joseph Merrick (1862-1890) que, durante mais de um século após a sua morte, teve como certo o diagnóstico da NF. Merrick ganhava a vida expondo-se em espetáculos freaks como o "Homem-Elefante: Metade homem e metade elefante". Os freak shows da era vitoriana, em Inglaterra, eram a oportunidade das pessoas com deficiência ganharem o seu próprio dinheiro ${ }^{28}$. No caso de Merrick, foi o único local em que ele conseguiu exercer algum trabalho remunerado. E, desta forma, a sua participação neste tipo de espetáculo garantiu a sua identidade como um trabalhador responsável pelo seu próprio sustento ${ }^{29}$. No entanto, após o banimento desses espetáculos em Inglaterra e na impossibilidade de conseguir algo remunerado, Merrick procurou o médico que havia conhecido em um de seus espetáculos, o doutor Frederick Treves. Os últimos anos de Merrick estiveram sob a tutela de Treves, dentro do Royal London Hospital. Em relação a vida de Merrick e a exposição/exploração de seu corpo, Rosenberg alerta que " o desejo de Merrick ser normal, apesar de sua desfiguração física, se tornou em uma fantasia, uma vez que ele termina ou como um show de espetáculo freak ou numa escola de medicina para ser examinado"30.
Apesar da morte física de Joseph Merrick contar para mais de um século, e o seu diagnóstico ter sido retificado para a síndrome de Proteus já nos anos 80 e confirmado definitivamente em $2013^{31}$, é a representação da personagem do Homem Elefante, aos olhos de Treves, como um exemplar de "monstruosidade", anormalidade, servilismo e dependente da caridade de outrem, que assombra a vida das pessoas com o diagnóstico da NF. Não por acaso, a menção ao personagem foi exposta somente em entrevistas com familiares.

Porque não tínhamos certeza. O pior crescimento que eu tinha visto... como o Homem Elefante, aquela coisa bruta, não com poucos [neurofibromas], mas o crescimento real. Eu não sabia muito até que [a criança] veio. Roussef (padrasto, 72 anos, aposentado, Inglaterra)

Às três semanas de vida [Angenor] começou a desenvolver um hemangioma no nariz, que não sei se sabes bem o que é, mas é uma espécie de tumor cheio de vasos sanguineos que se vai formando, $e$ que se não for tratado pode aumentar imenso. Eu li algures que... Por exemplo, não sei se já ouviste falar do Homem Elefante. [Sim]. Pronto, é esse tipo de coisas. Cartola (pai, 39 anos, antropólogo, Portugal)

Ela fez exatamente o que não deveria fazer, mas os pais fazem, né. Pesquisou a neurofibromatose, aí vem aqueles monstros, né. Um homem elefante [...] que parece que é a neurofibromatose tipo 1, então ela enlouqueceu, foi depois que ela pesquisou na internet. Raul (pai, 58 anos, engenheiro, Brasil)

\section{As consequências}

A partir do reconhecimento da concentração dos esforços na busca pela cura, é possível destacar alguns elementos chaves que atormentam as pessoas com o diagnóstico:

\section{A tirania da normalidade}

Em uma época de tirania do normal ${ }^{32}$ e determinismo do gene ${ }^{33}$ a predominância do discurso biomédico sobre as condições e suas representações sociais, fincada no coitado e na visão caritativa, separa a pessoa de sua trajetória de cidadão para a enquadrá-la na do doente. E como tal, há o desenrolar do julgamento moral sobre a pessoa que, nessa posição, pode ter alterada as suas relações no espaço médico e social ${ }^{34}$. Seguindo os estudos da deficiência que focalizam no meio social as barreiras para a plena cidadania das pessoas que convivem com alguma deficiência, as entrevistas demonstraram que as pessoas se 
sentem mais próximas daquelas que enfrentam as mesmas limitações, como dificuldade de locomoção ou na coluna, do que das que compartilham a mesma característica genética. Conclui-se que não é a informação genética que promove alguma ligação entre as pessoas mas o constrangimento vivido por causa das condições de saúde.

Sem sombra de dúvidas [estou mais próxima] das pessoas com problemas nas pernas. Sem sombra de dúvidas. Se eu ver uma pessoa na rua com o aparelho de Ilizarov, eu posso ir até ela e conversar, e eu poderei falar com ela sobre a época em que eu usei o mesmo aparelho. E se eu ver uma pessoa que eu acho que tenha NF, eu não vou falar com ela porque, novamente, como eu disse, não sabemos como é o caso dela. Coralina (28 anos, psicóloga/ pesquisadora, Inglaterra)

\section{A vivência da eugenia}

Relembro que a proposição de Rabinow para biossociabilidade foi elaborada a partir da observação de grupos de familiares ao redor da Neurofibromatose. Por isso, eu sentia tanta liberdade e acolhido quando estava com outros familiares. Ao ser confrontado pelas falas das pessoas com o diagnóstico, ao invés de encontrar a esperança dos tempos genômicos, fui tomado pela inquietação da evidência realizada por Shakespeare e $K{ }^{35}{ }^{35}$. De acordo com eles a sutileza do discurso genômico, na verdade, encobre as ações eugênicas em um campo onde o lucro com as pesquisas genéticas é como o "Santo Graal” das indústrias farmacêuticas. E mesmo que as políticas para as doenças raras e pesquisas genéticas foram amplamente voltadas para o mercado ${ }^{36}$, a euforia em torno da revolução da produção de "drogas órfãs" há 40 anos não resultou em ganhos para as pessoas que precisam destes medicamentos ${ }^{37}$. E, em uma época da irresistível tentação da "genetização" dos testes pré-natais como um qualquer "elixir da salvação" para eliminar a doença, podemos gerar os mesmos resultados que há 50 anos, quando da detecção dos fetos com má formação, especificamente relacionados à Síndrome de Down: a interrupção da gravidez ${ }^{38}$.

Como a minha mãe às vezes diz, quando se tem um filho a ideia é que o filho nasça perfeito. José (24 anos, estudante, Portugal)

\section{A (re)organização dos serviços de saúde}

A comparabilidade entre países desvendou a abertura para reflexões sobre (1) o Diagnóstico Genético Pré-Implantacional. Tanto em Portugal como em Inglaterra já existe legislação específica para a gravidez assistida. No Brasil não há legislação Federal específica sobre o assunto e as resoluções são realizadas através do Conse- lho Federal de Medicina ${ }^{39}$. O tema é complexo e, devido a grande diversidade cultural e dispersão geográfica do Brasil, assume outra magnitude ${ }^{40}$; (2) a atenção aos serviços primários. Assim como evidenciado na pesquisa sobre a condição hereditária hemocromatose ${ }^{41}$, as entrevistas indicaram que o conhecimento do diagnóstico pelo especialista possui um impacto negativo maior que quando realizado pelo pediatra ou quando acompanhada pelo médico da família. O diagnóstico de uma condição genética deve levar em conta, entre outras coisas, que é uma situação onde a informação é o recurso mais solicitado por quem vai recebê-lo. Portanto deve estar circundado de tempo e profissionais que a pessoa confia. E, seguramente, o médico da família é um ator importante na mitigação do impacto da informação e no fortalecimento do acolhimento da pessoa.

\section{Conclusão}

Bem, começando pelo fim, se o/a leitor/a franziu a testa sobre os pontuais argumentos da eugenia, compartilho que também tive a mesma reação ao conhecer essa comprovação de nossos tempos. E não foi fácil. Afinal, a medida que eu lia e construía o documento doutoral, a minha criança estava ao meu redor e próxima a mim. Mas assim como a verdade dói, ela também liberta. E, portanto, se a eugenia constrói a normalidade que inverte o natural desejo dos pais/mães buscarem as suas características em sua prole para uma jornada em que o esforço será conduzido para que a criança não "herda os seus genes", não há outro caminho a seguir que não seja o da contestação da normalidade e a sua (falsa) perfeição. E, para o reconhecimento dos tempos eugênicos, motivados pelo mercado e diluído nas "opções" por ele criadas, é preciso conscientizarmo-nos sobre o tempo da Eugenia flexível ${ }^{42}$. O termo emerge da análise da rotina das pessoas que convivem com o nanismo e podem utilizar o Diagnóstico Genético Pré-Implantacional como opção para a gravidez. E, pela flexibilidade, evita culpabilizar aqueles que utilizam alternativas de gravidez assistida e sublinha a complexidade de vivermos numa sociedade orientada pelo mercado e que coloca a escolha individual como um prêmio, ao mesmo tempo que aceita abertamente os padrões estabelecidos pela normalização genética. $\mathrm{O}$ seu entendimento é um alerta para recordarmos que a opção escolhida para a Síndrome de Down, mesmo após meio século de atuação das primei- 
ras associações, continua o mesmo, a interrupção da gravidez.

A Sociologia do Diagnóstico delimita e incentiva o foco não somente ao momento do diagnóstico como, também, aos seus desdobramentos na arena social. E sob a sua ótica, ao aceitarmos as pessoas com o diagnóstico de alguma condição genética como informantes-chave, vemos como as ações daqueles que dizem apoiá-las, principalmente pelas OPs, os colocam como pessoas carentes da ajuda de outrem. Ao invés de promover o incentivo à doença e à cura, podemos reconhecer que a informação genética gera condicionantes que afetam a vida das pessoas. E mesmo que a categoria Neurofibromatose ou qualquer condição genética precise do seu CID, antes de revelar o controle social pela nomeação da "doença" encontrada no gene, pode-se optar pelo reconhecimento das várias condições, presentes e futuras, impostas ao indivíduo que recebe o diagnóstico. Por isso, ao utilizarmos o termo condição genética em detrimento de doença, não se abandona as exigências da OMS, e (i) cria alternativas relativas aos fatores condicionantes para o desenvolvimento do cidadão e a garantia dos direitos humanos; (ii) alarga e reconhece as opções de cuidado para além da busca pela medicação; (iii) concentra-se na arena social e engrossa as fileiras do movimento da neurodiversidade e outros que evidenciam a impossibilidade da existência do indivíduo normal ${ }^{43}$.

Como visto, a pessoa que possui o diagnóstico peregrina por diferentes especialidades médicas, seja o pediatra, dermatologista, ortopedista, neurocirurgião, oftalmologista, fonoaudióloga enfim, uma variedade de profissionais que o capacitam a qualificar os diferentes serviços. Essa peregrinação não é exclusiva da NF e também é compartilhada por pessoas que possuem outras condições. Desta maneira, ao tomarmos essa população como informantes-chave dos próprios serviços de saúde, invertemos a marcha da caridade para entendermos como as suas contribuições podem revigorar a qualidade dos serviços de saúde.

\section{Referências}

1. Schieppati A, Henter J, Daina E, Aperia A. Why rare diseases are an important medical and social issue. Lancet 2008; 371(9626):2039-2041.

2. Rabeharisoa V, Callon M, Filipe AM, Nunes JA, Paterson F, Vergnaud F. The dynamics of causes and conditions: the rareness of diseases in French and Portuguese patients 'organizations' engagement in research. Paris: Institut Interdisciplinaire de l'Innovation; 2012. (CSI Working Papers Series). Report No.: 026.

3. Barbosa RL. Pele de Cordeiro? Associativismo e mercado na produção de cuidados para doenças raras. Lisboa: Chiado Editora; 2015.

4. Sousa AM, Monsores N. Política, Análise das características e dos preceitos normativos da Raras, Nacional de Atenção Integral às Pessoas com Doenças. Cad Ibero-Americanos Direito Sanitário 2015; 4(2):47-67.

5. Interfarma. Doenças raras: Contribuição para uma Politica Nacional. São Paulo: Intefama; 2013

6. Rohde DD. The Orphan Drug Act: An Engine of Innovation - At What Cost. Food Drug Law J 2000; 55(1):125-143
7. Akrich M, Nunes JA, Rabeharisoa V. Conclusions. In Akrich M, Nunes JA, Paterson F, Rabeharisoa V. The Dynamic of patient organizations in Europe. Paris: Paristech; 2008. p. 221-245.

8. Ellis C, Adams TE, Bochner AP. Autoethnography: An Overview. Forum Qual Soc Res 2011; 12(1):1-12.

9. Dheensa S, Williams GA. 'I have NF. NF does not have me.': An Interpretative Phenomenological Analysis of Coping with Neurofibromatosis Type 1. Heal Psychol Upadate 2009; 18(1):3-8.

10. Souza JF, Toledo LL, Ferreira MCM, Rodrigues LOC, Rezende NA. Neurofibromatose tipo 1: mais comum e grave do que se imagina. Rev da Assoc Médica do Bras 2009; 55(4):394-399.

11. Geller M, Bonalumi Filho A. Neurofibromatose. Rio de Janeiro: Centro Nacional de Neurofibromatose; 2012.

12. Mckeever K, Shepherd CW, Crawford H, Morrison PJ. An epidemiological, clinical and genetic survey of Neurofibromatosis type 1 in children under sixteen years of age. Ulster Med Soc 2008; 77(3):160-163. 
13. Ferner R, Huson SM, Evans DG. Neurofibromatoses in clincial practice. London: Springer; 2011.

14. Huson SM, Meredith AL, Sarfarazi M, Shaw DJ, Compston AS, Harper PS. Linkage analysis of peripheral neurofibromatosis (Von Recklinghausen disease) and chromosome 19 markers linked to myotonic dystrophy. J Med Genet 1986; 23(1):55-57.

15. Rabinow P. Artificiality and Enlightenment: From Sociobiology to Biosociality. In: Rabinow P. Essays on the Anthropology of Reason. New Jersey: Princeton University Press; 1996. p. 91-112.

16. Löwy I. Historiography of Biomedicine: "Bio", "Medicine", and IN Between. Hist Sci Soc 2011; 102(1):116122.

17. Löwy I. Prenatal diagnosis: The irresistible rise of the "visible fetus." Stud Hist Philos Sci Part C Stud Hist Philos Biol Biomed Sci 2014; 47(PB):290-299.

18. Blaxter M. Diagnosis as category and process: the case of alcoholism. Soc Sci Med 1978; 12:9-17.

19. Melo M, Gusso GDF, Levites M, Amaro E, Massad E, Lotufo PA, Zeidman P, Price CJ, Friston KJ. How doctors diagnose diseases and prescribe treatments: an fMRI study of diagnostic salience. Sci Rep 2017; 7(1):1304.

20. Blaxter M. The case of the vanishing patient? Image and experience. Sociol Heal Illn 2009; 31(5):762-778.

21. Brown P. Naming and Framing: The Social Construction of Diagnosis and Illness. J Health Soc Behav 1995; 35:34-52.

22. Jutel A. Putting a name on it - Dianosis in contemporany society. Baltimore: Johns Hopkins University Press; 2011.

23. Jutel A. From the bookshelf of a sociologist of diagnosis: A review essay. Contemp Sociol 2017; 46(3):257264.

24. Fialho JAL. Sociedade, escola e cidadania: a teoria em confronto com testemunhos de informantes chave. Lisboa: Universidade Nova de Lisboa; 2015.

25. Valladares L. Os dez mandamentos da observação participante. Rev Bras Ciências Sociais 2005; 22(63):153155.

26. Mol A. The logic of care. New York: Routledge; 2008.

27. Ablon J. Living with genetic disorder. London: Auburn House; 1999.

28. Graff V. Who was the freak show owner who discovered the Elephant Man? The Telegraph 2016.

29. Durbach N. Monstrosity, Masculinity and Medicine: Re-examining "the Elephant Man." Cult Soc Hist 2007; 4(2):193-213.

30. Rosenbaum SA. Hammerin' Hank: The right to be raunchy or FM Freak Show? Disabil Stud Q 2003; 23(3/4).

31. Huntley C, Hodder A, Ramachandran M. Clinical and historical aspects of the Elephant Man: Exploring the facts and the myths. Gene 2015; 555(1):63-65.

32. Fielder LA. The Tyranny of the Normal. Hast Cent $1984 ; 14(2): 40-42$.
33. Condit CM, Ofulue N, Sheedy KM. Determinism and mass-media portrayals of genetics. Am J Hum Genet 1998; 62(4):979-984.

34. Nesse RM. On the difficulty of defining disease: a Darwinian perspective. Med Health Care Philos 2001; 4(1):37-46.

35. Kerr A, Shakespeare T. Genetic politics from eugenics to genome. Manchester: New Clarion Press; 2002.

36. Wiest R, Neto GB, Cipriani F. A economia das doenças raras: incentivos e regulação. Econ Anal Law Rev 2014; 5(1):69-98.

37. Gittelman M. The revolution re-visited: Clinical and genetics research paradigms and the productivity paradox in drug discovery. Res Policy 2016; 45(8):15701585.

38. Löwy I. How genetics came to the unborn: 1960-2000. Stud Hist Philos Sci Part C Stud Hist Philos Biol Biomed Sci 2015; 47(PA):154-162.

39. Mendes MC, Costa APP. Diagnóstico genético pré-implantacional: prevenção, tratamento de doenças genéticas e aspectos ético-legais. Rev Ciências Médicas e Biológicas 2013; 12(3):374-379.

40. Horovitz DDG, Ferraz VEF, Dain S, Marques-de-Faria AP. Genetic services and testing in Brazil. J Community Genet 2013; 4(3):355-375.

41. Teixeira E, Lio Borlido-Santos J, Brissot P, Butzeck B, Courtois F, Evans RW, Fernau J, Nunes JA, Mulletth M, Paneque M, Pineau B, Porto G, Sorril R, Sanchez M, Swinkels DW, Toska K, Varkony J, the EFAPH, the European Federation of Associations of Patients with Haemochromatosis. Patient Perception, Preference and Participation The importance of the general practitioner as an information source for patients with hereditary haemochromatosis. Patient Education and Counseling 2014; 96(1):86-92.

42. Taussig KS, Rapp R, Heath D. Flexible Eugenics: Technologies of the Self in the Age of Genetics. Anthropol Mod Foucault, Gov Life Polit 2008; (April 2008):194212.

43. Holmes AJ, Patrick LM. The Myth of Optimality in Clinical Neuroscience. Trends Cogn Sci 2018; 22(3):241-257.

Artigo apresentado em 25/03/2019

Aprovado em 19/06/2019

Versão final apresentada em 21/06/2019 